\title{
Zeytin Yaprağının (Olea europaea L.) Diyabetik Sıçanlarda Bazı Biyokimyasal ve Hematolojik Parametreler Üzerine Etkisi
}

\begin{tabular}{l|c}
\hline Araştırma /Research & \\
Gelis Tarihi / Received & \\
03.10.2017 & Atilla TEMUR*, Mehmet Ali TEMIZ \\
Kabul Tarih / Accepted & 1.01.2018 \\
DOI & Yüzüncü Yll Üniversitesi, Eğitim Fakültesi,Van/Türkiye \\
10.28955/alinterizbd.341465 & *e-posta: temurat@yahoo.com \\
ISSN 2564-7814 & \\
e-ISSN 2587-2249 & \\
\hline
\end{tabular}

Öz: Bu çalışma, değişik oranlardaki zeytin yaprağı ekstraktının (Olive Leaf Extract-OLE) ve infüzyonunun streptozosin ile oluşturulmuş deneysel diyabetik sıçanların bazı biyokimyasal ve hematolojik parametreleri üzerine olası koruyucu etkisini araştırmak amacıyla planlanmıştır. Bu amaç doğrultusunda, 56 adet Wistar albino sıçan rastgele 7 gruba ayrıldı $(n=8)$. 21 günlük deneme sonunda biyokimyasal ve hematolojik analizleri yapıldı. OLE uygulanan grupların hepsinde RBC'ler istatiksel anlamda etkilenmezken, HBG, HCT, MCV'nin pozitif yönde etkilendiği görüldü $(\mathrm{p}<0,05)$. Diyabet+OLE-50 ve OLE-100 gruplarında WBC'ler, kontrol grubuna göre, anlamlı şekilde gerilerken $(\mathrm{p}<0,05)$, OLE-25 grubunda değişim gözlenmedi. Diyabet+OLE-25 grubunun kolesterol değerlerinde, kontrol grubuna göre, anlamlı bir düşüş gözlenirken ( $\mathrm{p}<0,05)$, diyabet+OLE-100 grubundaki artış istatiksel düzeyde önemliydi $(\mathrm{p}<0,05)$. Diyabet+OLE-50 grubundaki artış anlamlı değildi. Diyabet+OLE-25, diyabet+OLE-50 ve diyabet+OLE-100 gruplarında, trigliserid diyabet grubuna göre anlamlı derecede düşmüştü ( $\mathrm{p}<0,05$ ). İnfüzyon uygulanan diyabetli grupta RBC, HGB, HCT, MCV, MPV, PDW ve EOS pozitif yönde anlamlı şekilde artmıştı $(\mathrm{p}<0,05)$. İnfüzyon trigliserid, $\mathrm{LDL}, \mathrm{Cl}$ ve $\mathrm{Na}$ 'u negatif yönde, $\mathrm{HDL}, \mathrm{Mg}$ ve P'u pozitif yönde etkilediği belirlendi. OLE uygulanan gruplar içerisinde kolesterol ve trigliserid üzerine en etkili dozun OLE-25 mg/kg olduğu gözlendi. İnfüzyonun ise, HDL'yi pozitif yönde, LDL'yi de negatif yönde anlamlı şekilde etkilediği görüldü. Aynı şekilde kolesteroldeki düşüşün istatistiksel olarak önemsiz, trigliseritdeki düşüşün ise istatistiksel olarak önemli olduğu yönünde bulgular elde edildi.

Anahtar kelimeler: Diyabet, hematoloji, kolesterol, streptozosin, trigliserid.

\section{Effects of Olive Leaf (Olea europaea L.) Extract on Some Biochemical and Haematological Parameters in Diabetic Rats}

\begin{abstract}
This study was aimed to investigate the possible protective effects of different amount of olive leaf extracts and infusion on some biochemical and haematological parameters of streptozocin-induced experimental diabetic rats. For this purpose, 56 Wistar albino rats were randomly divided into 7 groups $(n=8)$. Biochemical and haematological analyses were performed at the end of the 21-day trial. It was observed that HGB, HCT, MCV were positively affected $(\mathrm{p}<0,05)$, while RBCs were not statistically significant affected in all OLE-applied groups. In diabetes+OLE50 and OLE-100 groups, WBCs significantly decreased compared to the that of control group ( $<<0,05)$, while statistically significant change was not observed in the OLE-25 group. The cholesterol values of the diabetes+OLE25 group were significantly lower than those of the control group $(p<0,05)$, while the increase in the diabetes+OLE100 group was significant at the statistical level $(\mathrm{p}<0,05)$. The increase in diabetes+OLE-50 group was not significant. In the diabetes+OLE-25, diabetes+OLE-50 and diabetes+OLE-100 groups, triglyceride decreased significantly $(p<0,05)$ in comparison to diabetic group. In the infused diabetic group, RBC, HGB, HCT, MCV, MPV, PDW and EOS were significantly increased in the positive direction ( $\mathrm{r}<0,05)$. Infusion was found to have negative effect on triglyceride; $\mathrm{LDL}, \mathrm{Cl}, \mathrm{Na}$. $\mathrm{HDL}, \mathrm{Mg}$ and $\mathrm{P}$ were found to be affected positively. It was determined that the most effective dose on cholesterol and triglycerides in OLE-administered groups is OLE- $25 \mathrm{mg} / \mathrm{kg}$. Infusion was found to have positive effect on HDL, while LDL was affected negatively. On the other hand, the decrease in cholesterol was found to be not statistically significant, while the decrease in triglyceride was significant.
\end{abstract}

Keywords: Diabetes, haematology, cholesterol, streptozotocin, triglyceride

Lütfen aşağıdaki şekilde atıf yapınız / Please cite this paper as follows:

Temur, A., \& Temiz, M. A., 2018. Zeytin Yaprağının (Olea europaea L.) Diyabetik Siçanlarda Bazı Biyokimyasal ve Hematolojik Parametreler Üzerine Etkisi. Alınteri Journal of Agriculture Sciences. 2018, 33(1): 13-19

\section{GIiRIŞ}

Zeytin ve ürünlerinden elde edilen bileşiklerin metabolik ve fizyolojik etkileri uzun yıllardır çalışıla gelen bir bileşen olmuştur. Zeytin yaprağı asırlardır yeryüzünde yetiştiği tüm bölgelerde halk tarafından çeşitli hastalıkların geleneksel tedavilerinde kullanılmaktadır (Soler-Rivas ve ark., 2000). Günümüzde bilimin, 
teknolojinin ve tıbbın gelişmesiyle birlikte yapılan çalışmalar sonucu geniş bir farmakolojik ve destekleyici özelliğe sahip olduğu gösterilmiştir (Somova ve ark., 2004). Zeytin yaprağı ekstraktının (Olive Leaf ExtractOLE) ana biyoaktif bileşenlerini oluşturan oleuropein, hidroksitirozol ve verbaskozit gibi polifenolik maddelerin metabolik etkilerinin çok yönlü olduğu bilinmektedir. Bu biyoaktif maddeler geniş spekturumlu fizyolojik ve farmakolojik etkinliğe sahiptirler (Somova ve ark., 2004; Andreadou ve ark., 2006).

Zeytin yapraklarından hazırlanan çayın DPPH ve hidrojen peroksit radikallerine karşı antioksidan etki gösterdiği bildirilmiştir. Zeytin yapraklarından elde edilen oleuropeinin oksidatif stres, enzimatik ve nonenzimatik antioksidanlar üzerine etkileri alloksan ile indüklenmiş diyabetik tavşanlarda araştırılmış; çalışma sonuçları, oleuropeinin diyabet ile indüklenen oksidatif stresi inhibe etme ve hipoglisemik olduğunu, ayrıca oksidatif stresle ilişkili komplikasyoların önlenmesinde faydalı olabileceğini göstermiştir (Al-Azzawi ve Alhamdami 2016).

Yıllardan beridir, bütün dünyada hastalıkların önlenmesi ve tedavisinde doğal ürünler insanlar tarafından kullanılmaktadır (Maimoona ve ark., 2011). Antibiyotik etkiye sahip doğal ürünlerin diyabetik tedavisinde kullanımına yönelik yapılan araştırmalar günümüzde büyük bir hız kazanmıştır (Chandra ve ark., 2007).

Diyabetin tedavisinde gerek halk arasında gerekse deneysel çalışmalar ile tıbbi bitkilerin kullanılması çok eskilere dayanmaktadır. Diyabetin en belirgin özelliği olan hipergliseminin ve bunun sonucunda gelişen oksidatif hasarın azaltılması amacıyla en çok kullanılan bitkiler arasında zeytinin yeri ayrıdır (Soler-Rivas ve ark., 2000). Diyabet, insülin salgılanmasında bozukluk, insülin aktivitesine direnç veya her iki kusurdan kaynaklanan hiperglisemi ile karakterize edilen metabolik bir bozukluktur. Kronik hiperglisemi nefropati, nöropati, retinopati ve ateroskleroz gibi mikrovasküler ile makrovasküler komplikasyonların gelişmesine neden olmaktadır (Karthikesan ve ark., 2010).

Zeytin yaprağının kan basıncını düşürdüğü ve koroner arterlerdeki kan akışını arttırdığı yönünde yayınlanmış çeşitli raporlar bulunmaktadır (Khayyal ve ark., 2002).

Son zamanlarda eritrosit ve özellikle trombosit indekslerini araştırmak için geliştirilen hematolojik analizörler sayesinde trombosit hacmi (MPV), trombokrit/plateletkrit (PCT) ve trombosit dağılım genişliği (PDW) gibi yeni trombosit indeksleri ile diyabet ilişkileri araştırılmış (Beyazit ve ark., 2012) ve bu indekslerin diyabetten başka akut pankreatit, miyokardiyal infarktüs ve ülseratif kolit gibi değişik hastalıklarında göstergesi olduğu ileri sürülmüştür (Beyazit ve ark., 2012).

Bu çalışma, Antalya ili yöresinde diyabet hastalığına karşı yaygın olarak kullanılan zeytin yaprağının streptozosin (STZ) ile deneysel diyabet oluşturulmuş sıçanların biyokimyasal ve hematolojik parametreler üzerine koruyucu bir etkisinin olup olmadığını belirlemek amacıyla planlanmıştır.

\section{MATERYAL VE YÖNTEM}

\section{Deney Hayvanı ve Zeytin Yapră̆ı Materyali}

Araştırmanın canlı materyali olan 250-350 g ağırlığında, 5-6 aylık, 88 adet sağlıklı Wistar albino erkek sıçanlar, Van Yüzüncü Yıl Üniversitesi Deney Hayvanları Ünitesinden temin edilerek standart plastik kafeslere yerleştirildi. Etkisi araştırılacak olan zeytin yaprağı (Ole aeuropaea L.) Antalya ili yöresinden Ağustos ayında toplanarak gölgede ve açık havada kurutuldu. Zeytin yaprakları öğütücüde toz haline getirilerek $-20^{\circ} \mathrm{C}$ 'de kullanılacağı zamana kadar hava almayan kilitli poşetlerde saklandı. YYÜ Herbaryumuna VANF-164715 kodu ile kaydı yapıldı. Bu çalışma, Yüzüncü Yıl Üniversitesi Hayvan Deneyleri Yerel Etik Kurulu'nun 25.08.2014 tarih ve 2014/90 sayılı izni ile gerçekleştirilmiştir.

\section{Zeytin Yaprağı Ekstraksiyonu}

Zeytin yaprağı ekstraktındaki fenolik bileşiklerin miktar tayini için $1 \mathrm{~g}$ toz haline getirilen zeytin yaprağ $50 \mathrm{ml}$ distile suya eklendi ve ağzı parafilm ile kapatıldı. Erlenin ışık almaması için etrafı alüminyum folyo ile sarıldı. Hot plate üzerinde $80^{\circ} \mathrm{C}, 750 \mathrm{rpm}$ de 12 saat boyunca ekstraksiyon işlemi gerçekleştirildi. Daha sonra süzüntü katı partiküllerden arındırılarak ağzı kapaklı falkon tüpte $+4^{\circ} \mathrm{C}, 3500 \mathrm{rpm}$ de 5 dakika santrifüj edildi. Elde edilen süpernatant $45 \mu$ m'lik PTFE filtre şırıngadan geçirilerek küçük partiküllerden arındırıldı ve içerik analizi için viallere aktarıldı. Deneklere uygulanacak ekstraksiyon için döner evaporatörde $37^{\circ} \mathrm{C}, 60 \mathrm{rpm}$ de yoğunlaştırma işlemi gerçekleştirildi. Ayrıca, $1,5 \mathrm{~g} / 100 \mathrm{ml}$ yaprak/su karışımı $80^{\circ} \mathrm{C}$ suda 5 dakika infüzyon işlemine tabi tutularak günlük ev tipi ekstraksiyonu yapıldı.

\section{HPLC ile Ekstrakt İçeriğinin Belirlenmesi}

OLE Yüksek Performans Sıvı Kromatografi (HPLC) cihazında zeytin yapraklarında bulunan başlıca biyoaktif madde olan oleuropein ile birlikte in vivo ve in vitro çalışmalarda daha sı etkinliği araştırılan Oleuropein, hidroksitirozol, tirozol ve verbaskozitin standartlara karşı kantitatif olarak miktar tayini tespiti yapıldı. Çalışma 
OLE'de bulunan oleuropein miktarına göre standardize edildi. HPLC'de ayırma işlemi için Zorbax SB, $5 \mu \mathrm{m}$, 150 x 4.6 mm C18 kolon kullanıldı.

\section{Deneysel Protokol}

Çalışma başlamadan önce sıçanlar bir süre ortama alıştırıldı. Her gruptaki sıçanların kan glukoz değerleri kuyruk bölümlerinden glukometre ile (Accu Check Nano, Germany) ölçülerek kayda geçildi. Uygulama başlatıldıktan sonra periyodik her hafta kan glukoz değerleri ölçülerek takip edildi. STZ soğuk sitrat tamponu içerisinde (pH: 4,5) $45 \mathrm{mg} / \mathrm{kg}$ vücut ağırlığı (bw) olacak şekilde taze olarak hazırlandı ve i.p yoldan kontrol grubu hariç diğer tüm gruplara uygulaması yapıldı (Tancrède ve ark., 1983). STZ uygulanmasından 3 gün sonra kan glukoz değerleri $200 \mathrm{mg} / \mathrm{dL}$ ve üzerinde olanlar diyabet olarak kabul edildi. Deneyde kullanılan sıçanlar rastgele 8 'erden 7 gruba ayrılarak aşağıdaki şekilde oluşturuldu.

Kontrol Grubu $(K G)$ : Siçanlara tek doz $1 \mathrm{ml}$ sitrat tamponu verildi.

Diyabetik Grup (DG): Siçanlara tek doz $45 \mathrm{mg} / \mathrm{kg}$ bw STZ i.p yolla,

Diyabet+OLE-25 (OLE-25): Diyabetik sıçanlara $25 \mathrm{mg} / \mathrm{kg}$ bw OLE intragastrik yolla her gün,

Diyabet+OLE-50 (OLE-50): Diyabetik siçanlara $50 \mathrm{mg} / \mathrm{kg}$ bw OLE intragastrik yolla her gün,

Diyabet+OLE-100 (OLE-100): Diyabetik sıçanlara $25 \mathrm{mg} / \mathrm{kg}$ bw OLE intragastrik yolla her gün,

Diyabet +Infüzyon (İnf): Diyabetik sıçanlara infüzyon işlemi yapılan çözeltiden $1 \mathrm{ml}$ intragastrik yolla her gün, Diyabet+Akarboz (Ak): Diyabetik siçanlara $150 \mathrm{mg} / \mathrm{kg}$ bw Glucobay (Bayer) intragastrik yolla uygulandı.

Bütün gruplar normal sıçan yemi ve musluk suyu ile ad libitum beslendi. Uygulama 21 gün devam ettirildi.

\section{Kan Örneklerinin Alınması}

Deneme sonunda sıçanlar ketaminle anestezi altına alınarak, biyokimya ve hematoloji testleri için gerekli olan kan, enjektörler yardımıyla hayvanların kalbinden alınarak EDTA'lı ve jelli tüplere aktarıldı. Biyokimya testleri için tüpler 2500 rpm'de 10 dakika santrifüj edilerek Roche Modular PP oto analizörde analizleri yapıldı.

Kan örneklerinde eritrosit ve trombosit indeksi değerleri ile akyuvar sayıları ve lökosit \% oranları Vetscan HM2 otomatik hematoloji analizörü ile belirlendi.

\section{ARAŞTIRMA BULGULARI VE TARTIŞMA}

Zeytin yaprağı ekstraksiyonu sonucunda HPLC ile analizinde oleuropein, hidroksitirozol, tirozol ve verbaskozit miktarları sırasıyla 15335,55; 461,05, 41,6 ve 357,6 $\mu \mathrm{g} / \mathrm{g}$ olarak tespit edilmiştir. Araştırmada elde edilen hematolojik değerler ve bunların istatiksel analizleri Çizelge 1'de, serum parametrelerinden elde edilen değerler ve istatiksel analizler de Çizelge 2'de verilmiştir. 
Alınteri Journal of Agriculture Sciences. 2018, 33(1): 13-19

Alınteri Zirai Bilimler Dergisi

A.TEMUR ve M. A. TEMIZ

Çizelge 1. Kontrol ve diyabet gruplarının hematolojik parametreleri

\begin{tabular}{|c|c|c|c|c|c|c|c|}
\hline \multirow{2}{*}{ Analizler } & KG & DG & OLE-25 & OLE-50 & OLE-100 & İnf & Ak \\
\hline & $\overline{\mathbf{X}} \pm \mathbf{S D}$ & $\overline{\mathbf{X}} \pm \mathbf{S D}$ & $\overline{\mathbf{X}} \pm \mathbf{S D}$ & $\overline{\mathbf{X}} \pm \mathbf{S D}$ & $\overline{\mathbf{X}} \pm \mathbf{S D}$ & $\overline{\mathbf{X}} \pm \mathbf{S D}$ & $\overline{\mathbf{X}} \pm \mathbf{S D}$ \\
\hline $\begin{array}{l}\text { RBC } \\
\left(10^{3} / \mu \mathrm{L}\right)\end{array}$ & $6,7 \pm 0,7$ & $7,0 \pm 0,7$ & $7,4 \pm 0,7$ & $7,2 \pm 0,7$ & $7,3 \pm 0,5$ & $8,0 \pm 0,8^{\mathrm{a}, \mathrm{b}, \mathrm{d}}$ & $6,5 \pm 0,7^{\mathrm{c}, \mathrm{f}}$ \\
\hline $\begin{array}{l}\text { HGB } \\
(\mathbf{g} / \mathbf{d L})\end{array}$ & $12,4 \pm 0,9$ & $12,6 \pm 1,1$ & $14,6 \pm 0,6^{\mathrm{a}, \mathrm{b}}$ & $14,3 \pm 0,8^{\mathrm{a}, \mathrm{b}}$ & $14,1 \pm 0,8^{\mathrm{a}, \mathrm{b}}$ & $14,7 \pm 0,5^{\mathrm{a}, \mathrm{b}}$ & $12,3 \pm 0,6^{\mathrm{c}, \mathrm{de}, \mathrm{f}}$ \\
\hline HCT $(\%)$ & $36,3 \pm 2,9$ & $39,3 \pm 3,3$ & $46,2 \pm 2,0^{\mathrm{a}, \mathrm{b}}$ & $41,6 \pm 1,9^{\mathrm{a}, \mathrm{c}}$ & $40,7 \pm 2,6^{\mathrm{a}, \mathrm{c}}$ & $42,6 \pm 4,1^{\mathrm{a}, \mathrm{c}}$ & $37,8 \pm 1,8^{\mathrm{c}, \mathrm{d}, \mathrm{f}}$ \\
\hline MCV (fL) & $54,3 \pm 1,8$ & $56,3 \pm 1,3$ & $57,9 \pm 1,8^{a}$ & $57,6 \pm 2,1^{\mathrm{a}}$ & $59,7 \pm 2,4^{\mathrm{a}, \mathrm{b}, \mathrm{d}}$ & $60,9 \pm 1,5^{\mathrm{a}, \mathrm{b}, \mathrm{c}, \mathrm{d}}$ & $58,0 \pm 1,0^{\mathrm{a}, \mathrm{f}}$ \\
\hline $\begin{array}{l}\text { MCH } \\
\text { (pg) }\end{array}$ & $18,5 \pm 0,5$ & $18,0 \pm 0,3$ & $19,4 \pm 0,6^{\mathrm{b}}$ & $19,9 \pm 1,4^{\mathrm{a}, \mathrm{b}}$ & $19,3 \pm 1,0^{\mathrm{b}}$ & $18,4 \pm 1,1^{\mathrm{d}}$ & $18,9 \pm 1,0$ \\
\hline $\begin{array}{l}\text { MCHC } \\
\text { (g/dL) }\end{array}$ & $34,5 \pm 0,6$ & $32,0 \pm 0,1^{\mathrm{a}}$ & $31,6 \pm 0,6^{\mathrm{a}}$ & $34,2 \pm 1,5^{\mathrm{b}, \mathrm{c}}$ & $34,4 \pm 1,8^{\mathrm{b}, \mathrm{c}}$ & $33,7 \pm 2,1^{\mathrm{b}, \mathrm{c}}$ & $32,7 \pm 0,6^{\mathrm{a}, \mathrm{d}, \mathrm{e}}$ \\
\hline $\operatorname{RDW}(\%)$ & $13,0 \pm 0,5$ & $12,9 \pm 0,7$ & $14,2 \pm 0,3^{\mathrm{a}, \mathrm{b}}$ & $13,2 \pm 0,5^{\mathrm{c}}$ & $14,0 \pm 0,4^{\mathrm{a}, \mathrm{b}, \mathrm{d}}$ & $13,2 \pm 0,4^{\mathrm{c}, \mathrm{d}}$ & $13,5 \pm 0,6^{b, c}$ \\
\hline $\begin{array}{l}\text { PLT } \\
\left(10^{3} / \mu \mathrm{L}\right)\end{array}$ & $342 \pm 26$ & $382,8 \pm 27^{\mathrm{a}}$ & $351 \pm 38^{\mathrm{a}}$ & $349 \pm 37$ & $373 \pm 41^{\mathrm{b}}$ & $373 \pm 41$ & $496 \pm 45^{\mathrm{a}, \mathrm{b}, \mathrm{c}, \mathrm{d}, \mathrm{e}, \mathrm{f}}$ \\
\hline MPV (fL) & $6,6 \pm 0,2$ & $7,4 \pm 0,3^{\mathrm{a}}$ & $7,2 \pm 0,2^{\mathrm{a}}$ & $7,3 \pm 0,3^{\mathrm{a}}$ & $7,0 \pm 0,1^{\mathrm{a}, \mathrm{b}, \mathrm{d}}$ & $8,0 \pm 0,1^{\mathrm{a}, \mathrm{b}, \mathrm{c}, \mathrm{d}, \mathrm{e}}$ & $6,9 \pm 0,2^{\mathrm{a}, \mathrm{b}, \mathrm{c}, \mathrm{d}, \mathrm{f}}$ \\
\hline PCT (\%) & $0,404 \pm 0,06$ & $0,268 \pm 0,03^{\mathrm{a}}$ & $0,275 \pm 0,06^{\mathrm{a}}$ & $0,293 \pm 0,09^{\mathrm{a}}$ & $0,233 \pm 0,05^{\mathrm{a}}$ & $0,214 \pm 0,05^{\mathrm{a}, \mathrm{d}}$ & $0,329 \pm 0,06^{\mathrm{a}, \mathrm{e}, \mathrm{f}}$ \\
\hline PDW & $15 \pm 0,10$ & $15,9 \pm 0,12^{\mathrm{a}}$ & $15,8 \pm 0,26^{\mathrm{a}}$ & $16 \pm 0,23^{\mathrm{a}, \mathrm{c}}$ & $15,7 \pm 0,09^{\mathrm{a}, \mathrm{d}}$ & $16,5 \pm 0,10^{\mathrm{a}, \mathrm{b}, \mathrm{c}, \mathrm{d}, \mathrm{e}}$ & $15,3 \pm 0,12^{\mathrm{a}, \mathrm{b}, \mathrm{c}, \mathrm{d}, \mathrm{e}, \mathrm{f}}$ \\
\hline $\begin{array}{l}\text { WBC } \\
\left(10^{3} / \mu \mathrm{L}\right)\end{array}$ & $8,1 \pm 1,1$ & $9,2 \pm 1,0^{\mathrm{a}}$ & $8,7 \pm 0,6$ & $7,9 \pm 0,9^{\mathrm{b}}$ & $7,7 \pm 1,1^{\mathrm{b}}$ & $7,8 \pm 1,1^{\mathrm{b}}$ & $6,9 \pm 0,5^{\mathrm{a}, \mathrm{b}, \mathrm{c}}$ \\
\hline LYM (\%) & $65,4 \pm 5,3$ & $37,9 \pm 4,4^{\mathrm{a}}$ & $42,7 \pm 3,4^{\mathrm{a}}$ & $53,4 \pm 6,4^{\mathrm{a}, \mathrm{b}, \mathrm{c}}$ & $58,0 \pm 4,0^{\mathrm{a}, \mathrm{b}, \mathrm{c}}$ & $66,4 \pm 4,5^{\mathrm{b}, \mathrm{c}, \mathrm{d}, \mathrm{e}}$ & $48,2 \pm 4,3^{\mathrm{a}, \mathrm{b}, \mathrm{e}, \mathrm{f}}$ \\
\hline MON (\%) & $12,2 \pm 1,4$ & $8,1 \pm 1,7^{\mathrm{a}}$ & $3,3 \pm 0,5^{\mathrm{a}, \mathrm{b}}$ & $22,2 \pm 2,2^{\mathrm{a}, \mathrm{b}, \mathrm{c}}$ & $10,3 \pm 1,6^{\mathrm{a}, \mathrm{b}, \mathrm{c}, \mathrm{d}}$ & $12,0 \pm 1,5^{\mathrm{b}, \mathrm{c}, \mathrm{d}, \mathrm{e}}$ & $6,9 \pm 0,7^{\mathrm{a}, \mathrm{c}, \mathrm{d}, \mathrm{e}, \mathrm{f}}$ \\
\hline BAS (\%) & $0,9 \pm 0,14$ & $1,15 \pm 0,23$ & $0,82 \pm 0,32$ & $1,28 \pm 0,29^{\mathrm{a}, \mathrm{c}}$ & $1,38 \pm 0,29^{\mathrm{a}, \mathrm{c}}$ & $0,73 \pm 0,23^{\mathrm{b}, \mathrm{d}, \mathrm{e}}$ & $1,27 \pm 0,42^{\mathrm{a}, \mathrm{c}, \mathrm{f}}$ \\
\hline $\operatorname{EOS}(\%)$ & $0,82 \pm 0,26$ & $1,5 \pm 0,4^{\mathrm{a}}$ & $1,17 \pm 0,21$ & $1,48 \pm 0,28^{\mathrm{a}}$ & $1,28 \pm 0,26^{\mathrm{a}}$ & $1,25 \pm 0,26^{\mathrm{a}}$ & $2,42 \pm 0,63^{\mathrm{a}, \mathrm{b}, \mathrm{c}, \mathrm{d}, \mathrm{e}, \mathrm{f}}$ \\
\hline
\end{tabular}

$\mathrm{p}<0,05$ : Anlamlılık derecesi, a: Kontrol grubu ile arasındaki fark anlamlıdır $(\mathrm{p}<0,05)$. b: Diyabet grubu ile arasındaki fark anlamlıdır $(p<0,05)$. c: $D+25$ grubu ile arasındaki fark anlamlıdır $(p<0,05)$. d: $D+50$ grubu ile arasındaki fark anlamlıdır ( $p<0,05)$. e: $D+100$ grubu ile arasındaki fark anlamlıdır ( $<<0,05)$. f: $\mathrm{D}+$ İnf grubu ile arasındaki fark anlamlıdır $(\mathrm{p}<0,05)$.

Deney hayvanları 21 günlük çalışma süresi boyunca normal göründüler; herhangi bir fiziksel veya davranışsal değişiklik ve herhangi bir deney grubunda ölüm gözlenmemiştir.

Bütün vücut hücrelerinde olduğu gibi kan hücreleri de plazma lipidlerinin miktarındaki değişikliklerden etkilenmektedir. Bu nedenle, plazma kolesterol düzeyindeki artışlar ya da azalışlar özellikle alyuvarların membran lipid kompozisyonunu da etkilemektedir (Choi ve Pai, 2004). Hiperkolesterolemiye bağl1 deformobilite özelliğindeki azalma bu hücrelerin yaşam sürelerini kısaltabildiği gibi hemolize yatkınlıklarını da artırabilmektedir (Meurs ve ark., 2005). Total kolesterol, trigliserid, HDL ve LDL kolesterol konsantrasyonlar1 kardiyovasküler hastalık indikatörleridir (Thomas, 2002). Tip 2 diyabetli hastaların çoğu 1lımlı hipertrigliseridemi ve düşük HDL kolesterol seviyeleri ile karakterize olup, hipertrigliseridemi koroner arter hastalığı için bağımsız bir risk faktörüdür (Ginsberg, 1999).

$\mathrm{Bu}$ çalışmada trigliseridin, diyabet grubunda etkilenmediği, fakat OLE uygulanan grupların hepsinde, kontrol grubuna göre anlamlı derecede düştŭğü görüldü $(\mathrm{p}<0,05)$. OLE grupları kendi aralarında değerlendirildiğinde de, uygulanan miktara bağlı olarak OLE-25 grubuna göre trigliseritin arttı̆̆ tespit edildi $(\mathrm{p}<0,05)$. Diğer taraftan kolesterol düzeyi, kontrol grubuna göre, OLE-25 grubunda anlamlı bir şekilde düşmesine rağmen ( $<<0,05)$, diğer gruplarda doz artışına bağlı olarak anlamlı bir yükselme görülmüştür $(\mathrm{p}<0,05)$. Daha önce yapılan buna benzer bir çalışmada (Eidi ve ark., 2009) diyabetik sıçanların trigliserit ve kolesterol düzeylerinin arttı̆ğ bildirilmiştir. $\mathrm{Bu}$ sonuç yapılan bu çalışmadaki trigliserit düzeyi için benzerlik göstermekle birlikte, kolesterol değeri için zitlık ifade etmektedir. Elde edilen sonuçlara göre, özellikle $25 \mathrm{mg} / \mathrm{kg}$ OLE'nin etkin bir şeklide kolesterol ve trigliserit kontrolünde önemli olabildiği, fakat doz artışına bağlı olarak bu iki parametrenin de arttığı belirlendi $(\mathrm{p}<0,05)$. Kolesterol infüzyon grubunda kontrol grubu değerlerine en yakın düzeyde kalmıştır. Burada doza bağlı olarak trigliserit ve kolesterol miktarındaki artı̧s dikkat çekmektedir (Çizelge 2).

Kayaalp (2002) tarafindan, yüksek dansiteli lipoproteinler (HDL), plazmadan trigliseridlerin ve kolesterolün temizlenmesinde ve kolesterolün dokulardan karaciğere geri taşınmasında ve metabolizmasında önemli rol 
oynadıkları, dolayısı ile anti-aterojenik etkinlik gösterdikleri belirtilmektedir. Elde edilen LDL ve HDL sonuçları, diyabet grubunda anlamlı şekilde negatif yönde etkilendiği, OLE uygulanan gruplarda, kontrol grubuna göre, her iki parametrede doza bağlı olarak istatiksel düzeyde yükseldiği görüldü (p<0,05). İnfüzyon grubunda ise, LDL anlamlı derecede düşerken $(\mathrm{p}<0,05)$, HDL anlamlı derecede yükselmişti $(\mathrm{p}<0,05)$. Bu parametreler kendi aralarında değerlendirildiğinde de, Kayaalp (2002)'ın belirttiği anti-aterojenik etkinin olduğunu söyleyemeyiz. Zira söz konusu parametreler -HDL, trigliserid ve kolesterol- arasında doğru bir ilişki olduğu görüldü. Özbek ve ark., (2006)'da yaptıkları başka bir çalışmada, bu ilişkinin olmadığını belirtmektedirler.

Çizelge 2. Kontrol ve diyabet gruplarının biyokimyasal parametreleri

\begin{tabular}{|c|c|c|c|c|c|c|c|}
\hline \multirow{2}{*}{ Analizler } & KG & DG & OLE-25 & OLE-50 & OLE-100 & Inf & Ak \\
\hline & $\overline{\mathbf{X}} \pm \mathbf{S D}$ & $\overline{\mathbf{X}} \pm \mathbf{S D}$ & $\overline{\mathbf{X}} \pm \mathbf{S D}$ & $\overline{\mathbf{X}} \pm \mathbf{S D}$ & $\overline{\mathbf{X}} \pm \mathbf{S D}$ & $\overline{\mathbf{X}} \pm \mathbf{S D}$ & $\overline{\mathbf{X}} \pm \mathbf{S D}$ \\
\hline Kolesterol & $64,8 \pm 3,7$ & $51,8 \pm 8,7^{\mathrm{a}}$ & $45,8 \pm 6,6^{\mathrm{a}}$ & $70,0 \pm 6,7^{\mathrm{b}, \mathrm{c}}$ & $74,3 \pm 6,2^{\mathrm{a}, \mathrm{b}, \mathrm{c}}$ & $62,2 \pm 2,8^{\mathrm{b}, \mathrm{c}, \mathrm{d}, \mathrm{e}}$ & $59,5 \pm 5,1^{\mathrm{b}, \mathrm{c}, \mathrm{d}, \mathrm{e}}$ \\
\hline Trigliserid & $77,0 \pm 3,5$ & $79,6 \pm 6,2$ & $46,3 \pm 4,9^{\mathrm{a}, \mathrm{b}}$ & $67,2 \pm 6,0^{\mathrm{a}, \mathrm{b}, \mathrm{c}}$ & $66,8 \pm 6,8^{\mathrm{a}, \mathrm{b}, \mathrm{c}}$ & $64,5 \pm 6,5^{\mathrm{a}, \mathrm{b}, \mathrm{c}}$ & $64,2 \pm 5,7^{\mathrm{a}, \mathrm{b}, \mathrm{c}}$ \\
\hline LDL & $21,0 \pm 2,3$ & $12,3 \pm 2,2^{\mathrm{a}}$ & $14,5 \pm 1,9^{\mathrm{a}}$ & $17,8 \pm 2,8^{\mathrm{a}, \mathrm{b}, \mathrm{c}}$ & $24,5 \pm 2,3^{\mathrm{a}, \mathrm{b}, \mathrm{c}, \mathrm{d}}$ & $16,2 \pm 3,5^{\mathrm{a}, \mathrm{b}, \mathrm{d}}$ & $14,8 \pm 1,9^{\mathrm{a}, \mathrm{d}, \mathrm{e}}$ \\
\hline HDL & $26,0 \pm 0,9$ & $21,5 \pm 2,1^{\mathrm{a}}$ & $20,8 \pm 2,5^{\mathrm{a}}$ & $34,2 \pm 3,3^{\mathrm{a}, \mathrm{b}, \mathrm{c}}$ & $32,3 \pm 2,3^{a, b, c}$ & $28,7 \pm 2,0^{\mathrm{a}, \mathrm{b}, \mathrm{c}, \mathrm{d}, \mathrm{e}}$ & $19,0 \pm 2,0^{\mathrm{a}, \mathrm{d}, \mathrm{e}, \mathrm{f}}$ \\
\hline $\mathbf{T P}$ & $5,9 \pm 0,1$ & $6,2 \pm 0,1^{\mathrm{a}}$ & $6,0 \pm 0,1$ & $6,7 \pm 0,3^{\mathrm{a}, \mathrm{b}, \mathrm{c}}$ & $6,8 \pm 0,2^{\mathrm{a}, \mathrm{b}, \mathrm{c}}$ & $5,7 \pm 0,3^{\mathrm{b}, \mathrm{c}, \mathrm{d}, \mathrm{e}}$ & $6,8 \pm 0,4^{\mathrm{a}, \mathrm{b}, \mathrm{c}, \mathrm{f}}$ \\
\hline $\mathbf{C a}$ & $9,8 \pm 0,3$ & $10,0 \pm 0,4$ & $9,6 \pm 0,5$ & $11,3 \pm 0,9^{\mathrm{a}, \mathrm{b}, \mathrm{c}}$ & $12,0 \pm 1,0^{\mathrm{a}, \mathrm{b}, \mathrm{c}}$ & $10,1 \pm 0,6^{\mathrm{d}, \mathrm{e}}$ & $10,3 \pm 0,2^{\mathrm{d}, \mathrm{e}}$ \\
\hline Cl & $104,3 \pm 1,4$ & $96,3 \pm 1,5^{\mathrm{a}}$ & $94,0 \pm 4,2^{\mathrm{a}}$ & $100,3 \pm 3,9^{\mathrm{a}, \mathrm{b}, \mathrm{c}}$ & $100,8 \pm 1,6^{\mathrm{a}, \mathrm{b}, \mathrm{c}}$ & $99,0 \pm 2,7^{\mathrm{a}, \mathrm{c}}$ & $94,8 \pm 1,8^{\mathrm{a}, \mathrm{d}, \mathrm{e}, \mathrm{f}}$ \\
\hline $\mathbf{N a}$ & $140,3 \pm 1,9$ & $135,0 \pm 2,4^{\mathrm{a}}$ & $134,8 \pm 3,1^{\mathrm{a}}$ & $141,7 \pm 2,8^{\mathrm{b}, \mathrm{c}}$ & $143,0 \pm 4,2^{\mathrm{b}, \mathrm{c}}$ & $133,8 \pm 1,7^{\mathrm{a}, \mathrm{d}, \mathrm{e}}$ & $136,3 \pm 2,0^{\mathrm{a}, \mathrm{d}, \mathrm{e}}$ \\
\hline $\mathbf{K}$ & $5,8 \pm 0,4$ & $6,0 \pm 0,4$ & $6,0 \pm 0,8$ & $6,8 \pm 0,7^{\mathrm{a}, \mathrm{b}, \mathrm{c}}$ & $6,4 \pm 0,9$ & $5,9 \pm 0,5^{\mathrm{d}}$ & $6,4 \pm 0,3$ \\
\hline Mg & $2,4 \pm 0,1$ & $2,5 \pm 0,2$ & $2,8 \pm 0,1^{\mathrm{a}}$ & $2,6 \pm 0,2$ & $2,6 \pm 0,3$ & $3,1 \pm 0,4^{\mathrm{a}, \mathrm{b}, \mathrm{c}, \mathrm{d}, \mathrm{e}}$ & $2,7 \pm 0,2^{\mathrm{a}, \mathrm{f}}$ \\
\hline $\mathbf{P}$ & $6,8 \pm 0,7$ & $5,9 \pm 0,9$ & $7,7 \pm 0,9^{b}$ & $9,2 \pm 1,1^{\mathrm{a}, \mathrm{b}, \mathrm{c}}$ & $11,1 \pm 1,2^{\mathrm{a}, \mathrm{b}, \mathrm{c}, \mathrm{d}}$ & $9,1 \pm 0,8^{\mathrm{a}, \mathrm{b}, \mathrm{c}, \mathrm{e}}$ & $8,3 \pm 0,6^{\mathrm{a}, \mathrm{b}, \mathrm{e}}$ \\
\hline
\end{tabular}

$\mathrm{p}<0,05$ : Anlamlılık derecesi, a: Kontrol grubu ile arasındaki fark anlamlıdır $(\mathrm{p}<0,05)$. b: Diyabet grubu ile arasındaki fark anlamlıdır $(p<0,05)$. c: $D+25$ grubu ile arasindaki fark anlamlıdır $(p<0,05)$. d: D+50 grubu ile arasındaki fark anlamlıdır $(p<0,05)$. e: $D+100$ grubu ile arasındaki fark anlamlıdır $(\mathrm{p}<0,05)$. f: $\mathrm{D}+$ İnf grubu ile arasındaki fark anlamlıdır $(\mathrm{p}<0,05)$.

RBC'ler yüksek hücresel HGB içerdiklerinden ve membranlarında yüksek oranda yağ asidi bulundurduğundan dolayı oksidatif hasara maruz kalmaktadırlar (Tedesco 2000). 50 mg/kg OLE dozunun RBC, HGB, HCT, MCV, $\mathrm{MCH}$ ve MCHC değerleri üzerine herhangi bir olumlu etkisinin olmadığı belirtilmektedir (Gao ve ark., 2013). Aynı şekilde bu çalışmada RBC'ler, ne diyabet grubunda ne de farklı dozlarda OLE uygulanan gruplarda istatiksel düzeyde etkilenmemesine rağmen, diğer parametrelerin pozitif yönde etkilendiği görüldü. Fakat infüzyon uygulanan grupta anlamlı düzeyde ve pozitif yönde etkilenme tespit edildi $(\mathrm{p}<0,05)$. OLE içerisinde fenolik antioksidan bileşiklerinin olduğu ve serbest radikalleri yakalama özelliğinin bulunduğu belirtilmektedir (Fabiani ve ark., 2008; Geyikoğlu ve ark., 2016). Anemi, diyabetli bireylerde diyabet olmayanlara göre daha s1k rastlanan olgulardan biridir. Diyabetten dolayı artan oksidatif stres, kan hücreleri de dâhil bütün dokuları etkilemektedir. Dolayısıyla OLE'nin söz konusu bu özelliklerinden dolayı STZ kaynaklı anemiyi önlediği ve bu hücreleri koruduğu söylenebilir.

Diyabette hemoglobin, albumin, kollajen, LDL veya kristalin proteinler gibi çeşitli proteinlerin enzimatik olmayan glikasyona maruz kaldıkları bildirilmiştir (Klein 1995). Diyabetik sıçanlardaki hemoglobin miktarındaki azalma tüm dokulardaki protein sentezindeki azalmaya bağlı olduğu ifade edilmiştir (Gayathrı ve Kannabıran 2009). Bu çalışmada da HGB ile Çizelge 2'de verilen total protein (TP) arasındaki bu ilişkinin negatif yönde değil, pozitif yönde olduğu görüldü. Aynı şekilde, HGB diyabet grubunda herhangi bir değişime uğramazken, OLE verilen grupların hepsinde, kontrol grubuna ve diyabet grubuna göre, anlamlı bir artış gözlenmiştir $(p<0,05)$. Farklı dozlardaki OLE grupları kendi aralarında değerlendirildiğinde herhangi bir değişimin olmadığ̣ görüldü. Bu bulgu HGB'nin OLE den etkilendiği fakat doza bağlı bir değişimin olmadığı görülmüştür.

Geyikoğlu ve ark., (2016) yaptığı bir çalışmada, oleuropeinin 200 mg/kg'lık dozlarda bu parametreler üzerinde benzer etkiler sağladığını, $50 \mathrm{mg} / \mathrm{kg}$ oleuropeinin herhangi bir olumlu etki göstermediğini belirtmişlerdir. Aynı zamanda $100 \mathrm{mg} / \mathrm{kg}$ oleuropein uygulanmasindan sonra sisplatin alan grubun HGB, MCV, MCH, MCHC ve HCT düzeylerinde belirgin bir etki tespit etmişlerdir. Hematokrit değeri, plazma hacmine, alyuvar şekil ve büyüklüğüne bağlı olduğu göz önüne alındığında kan sıvısının azaldığı durumlarda hematokrit değerin arttığı bildirilmiştir (Yılmaz 2000). Yapılan araştırmada, her ne kadar RBC düzeylerinde anlamlı bir artış görülmediyse de, sayısal anlamda yine de bir artış gözlendi. Aynı zamanda MCV nin de arttı̆ğ belirlendi. Bu artış, OLE 
uygulanan bütün gruplarda ve infüzyon grubunda, hematokrit değerlerinde artışa sebep olmuştur. Diyabet grubunda ise hematokrit değeri değişmemişti. $\mathrm{MCH}$ ve $\mathrm{MCV}$ indekslerinin sadece STZ uygulamasından etkilenmediği, fakat MCV'nin 25-50 ve $100 \mathrm{mg} / \mathrm{kg}$ OLE uygulaması ve infüzyon grubunda, kontrol grubuna göre, anlamlı bir artışın olduğu tespit edildi $(\mathrm{p}<0,05)$. MCH'nin diyabet grubu ile mukayesesinde, her üç OLE grubunda da anlamlı arttı̆̆ gözlendi $(\mathrm{p}<0,05)$.

RDW de ise değerler dalgalı bir seyir gösterdi. OLE-25 ve $100 \mathrm{mg} / \mathrm{kg}$ gruplarında pozitif yönde değişim gözlendi. OLE-50 mg/kg ve infüzyon grubunda kontrol grubuna göre, istatiksel düzeyde değişim gözlenmedi $(\mathrm{p}<0,05)$.

Farklı çalışmalarda eritrosit ve trombosit indekslerinin etkilendiği (Beyazit ve ark., 2012, Baynes ve ark., 1988), trombosit sayısı ile trombosit hacmi arasında önemli negatif ilişkiler bulunduğu kaydedilmiştir (Baynes ve ark., 1988). Trombosit fonksiyonlarını en iyi yansıtan belirteçlerden biri olan MPV'nin diyabet, akut pankreatit, miyokardial infarktüs ve ülseratif kolit gibi değişik hastalıklar için önemli bir gösterge olabileceği ileri sürülmüştür (Beyazit ve ark., 2012; Baynes ve ark., 1988).

$\mathrm{Bu}$ çalışmada literatür verileri ile paralellik gösterecek şekilde, diyabet grubu trombosit değerlerinde pozitif yönde anlamlı artış gözlendi. İnfüzyon ve OLE uygulanan gruplarda bu parametrenin kontrol grubu değerlerine döndüğü belirlendi.

Düşük dereceli inflamasyon göstergesi olan lökositoz diyabetin yanı sıra obezite de gözlenebilen bir olgudur (Mahmoud 2013). Düşük oleuropein dozu (50 ve $100 \mathrm{mg} / \mathrm{kg}$ ) WBC'lerin, bazofilin, monositin, eozinofilin, lenfositin, nötrofilin \% oranlarını ve trombosit sayısını yetersiz bir şekilde artırdığı bildirilmektedir (Geyikoğlu ve ark., 2016). Oysa sunulan bu çalışmada, OLE-50 ve $100 \mathrm{mg} / \mathrm{kg}$ uygulanan gruplarda eozinofil, bazofil, monosit ve lenfositlerin sayılarında önemli artışların olduğu belirlendi. Aynı zamanda diyabet grubunda WBC ve trombositlerde istatiksel düzeyde artış gözlenirken, doz artışına bağlı olarak WBC lerdeki 1lımlı lökopeni dikkat çekti.

\section{SONUÇ VE ÖNERILER}

Sonuç olarak, zeytin yaprağı ekstraktının ve infüzyonunun biyokimyasal ve hematolojik parametreler üzerine anlamlı etkisinin olduğu belirlendi. Kolesterolün OLE-25 grubunda, trigliseritin ise OLE uygulanan bütün gruplarda anlamlı derecede düştüğü görüldü. Kolesterol, trigliserit, HDL, LDL ve TP OLE deki doz artışına bağlı olarak arttığ 1 tespit edildi. İnfüzyonun ise, HDL'yi pozitif yönde, LDL'yi de negatif yönde anlamlı şekilde etkilediği görüldü. Ayrıca, kolesterolü önemsiz, trigliseriti de önemli olacak şekilde düşürdüğü yönünde bulgular elde edildi. OLE nin hematolojik parametrelerden RBC'ler üzerine istatiksel anlamda herhangi bir etkisinin olmadığı, fakat RBC bileşenlerini (MCV, MCH, MCHC) etkilediği, HCT ve HGB'yi de önemli derecede artırdığı belirlendi. WBC'ler de negatif yönde etkilendi. infüzyonun RBC ve bileşenleri üzerine ve HCT, HGB üzerine pozitif yönde istatiksel düzeyde etkili olduğu tespit edildi.

Zeytin yaprağının halk arasında birçok hastalığı tedavi edici yönü olduğuna inanılmaktadır. Bu inanışın bilimsel bir tabanının olup olmadığını belirlemek amacıyla, bu alandaki çalışmalara hız verilerek, söz konusu bitkinin farmakolojik etkinliğinin daha ayrıntılı bir şekilde ortaya konulması gerekmektedir.

\section{KAYNAKLAR}

Al-Azzawie, H.F., Alhamdani, MS., 2006. Hypoglycemicand antioxidanteffect of oleuropein in alloxan-diabeticrabbits. Life Sci, 78, 1371-7.

Andreadou, I., Iliodromitis, E.K., Mikros, E., Constantinou, M., Agalias, A., Magiatis, P., Skaltsounis, A.L., Kamber, E., Tsantili-Kakoulidou, A. and Kremastinos, D.T, 2006. The olive constituentol europein exhibits anti-ischemic, antioxidative, and hypolipidemic effects in anesthetized rabbits. Journal of Nutrition, 136, 2213-2219.

Baynes, R.D., Lamparellı, R.D.V., Chetty, N., Atkınson, P., Bezwoda, W.R.A. ve Gear, J., 1988. Platelet parameters: Part II. Platelet volume-number relationships in various normal and disease states. SAMJ, 73, 39-43.

Beyazit, Y., Sayilir, A., Torun, S., Suvak, B., Yeşil, Y. and Purnak, T., 2012. Mean platelet volume as an indicator of disease severity in patients with acute pancreatitis. Clin Res Hepatol Gastroenterol, 36, 162-8.

Chandra, A., Mahdi, A.A., Ahmad, S. and Singh, R.K., 2007. Indian herbs result in hypoglycemic responses in streptozotocin induced diabetic rats. Nutr. Res, 27, 161-168.

Choi, J.W., Pai, S.H., 2004. Influences of hypercholesterolemia on red cell indices and erythrocyte sedimentation rate in elderly persons. Clin Chima Acta, 341, 117-121.

Eidi, E., Eidi, M., Darzi, R., 2009. Antidiabetic effect of Olea europaea L. in normal and diabetic Rats. Phytotherapy Research, 23, 347-350.

Gao, L.P., Li, Z., Guo, Z.Y., 2013. The effects of vitamin Con DDP-induced anemia in rats. Toxicol Mech Methods, 23, $383-388$.

Gayathrı, M., Kannabiran, K., 2009. The Effects of Oral Administration of an Aqueous Extract of Ficus bengalensis Stem Bark on Some Hematological and Biochemical Parameters in Rats with Streptozotocin-Induced Diabetes. Turk J Biol, 33, 9-13. 
Geyikoglu, F., Colak, S., Turkez, H., Bakır, M. and Koç, K., 2016. Oleuropein Ameliorates Cisplatin-induced HematologicalDamages Via Restraining Oxidative Stress and DNA Injury. Indian J Hematol Blood Transfus, DOI $10.1007 / \mathrm{s} 12288-016-0718-3$

Ginsberg, H.N., 1999. Identification and treatment of hypertri-glyceridemia as a risk factor for coronary heart disease. Curr Cardiol Rep, 1: 2337.

Karthikesan, K., Pari, L. ve Menon, V.P., 2010. Combined treatment of tetrahydro curcumin and chlorogenic acid exert spotential antihyperglycemic effect on streptozotocin nicotinamide induced diabeticrats. Gen. Physiol. Biophys, 29, 23-30.

Kayaalp, O., 2002. Rasyonel tedavi yönünden tıbbi farmakoloji. Onuncu baskı, Hacettepe-TAȘ, Ankara.

Khayyal, M.T., El-Ghazaly, M.A., Abdallah, D.M., Nassar, N.N., Okpanyi, S.N. and Kreuter, M.H., 2002. Blood pressure lowering effect of an olive leaf extract (Olea europaea) in L-NAME induced hypertension in rats. Arzneimittelforschung, 52, 797-802.

Klein, R., 1995. Hyperglycemia and microvascular and macrovascular disease in diabetes. Diabetes Care, 18, $258-268$.

Mahmoud, A.M., 2013. Hematological alterations in diabetic rats-role of adipocytokines and effect of citrus flavonoids. EXCLI Journal, 12, 647-57.

Maimoona, A., Naeem, I., Saddiqe, Z. and Jameel, K., 2011. A review on biological, nutraceutical and clinical aspects of French maritimepine bark extract. J.Ethnopharmacol,133, 261-277.

Meurs, I., Hoekstra, M., Van Wanrooij, E.J.A., Hildebrand, R.B, Kuiper, J., Kuipers, F., Hardeman, M.R., Van Berkel, T.J.C. and Van Eck, M., 2005. HDL cholesterol levels are an important factor for determining the lifespan of erythrocytes. Exp Hematol, 33, 1309-1319.

Özbek, H., Cengiz, N., Him, A., Uğraş, S., Özgökçe, F. ve Erdoğan, E., 2006. Yüksek kolesterollü diyetle beslenen sıçanlarda Foeniculum vulgare P. mill. (rezene) tohumlarının kan kolesterol seviyesi üzerine etkis, Genel Tıp Derg, 16, 177-180.

Soler-Rivas, C., Espin, J.C. and Wichers, H.J., 2000. Oleuropein and related compounds. Journal of Agricultural and Food Chemistry, 80, 1013-1023.

Somova, L.I., Shode, F.O., Mipando, M., 2004. Cardiotonic and antidysrhyth-mic effects of leanolic and ursolic acids, methyl maslinate and uvaol. Phytomedicine, 11, 121-129.

Tancrède, G., Rousseau-Migneron, S. and Nadeau, A., 1983. Long-term changes in the diabetic state induced by different doses of streptozotocin in rats. British Journal of Experimental Pathology, 64, 117-123.

Tedesco, I., Russo, M., Russo, P., Carraturo, A., Faruolo, C., Moio, L. and Palumbo, R., 2000. Antioxidant effect of red wine polyphenols on red blood cells. J Nutr Biochem, 11, 114-119.

Thomas, R.M., 2002. Oxidative stress and lipid in diabetes. A role in endothelium vasodilator dysfunction. Vasc Med, 1, 195-204.

Yılmaz, B., 2000. Fizyoloji. Canlılık olaylarıyla ilgili fiziksel ve kimyasal kurallar, beden sıvıları, kan, bağışılık, alerji, lenf, kemik iliği ve kan dolaşımı, Ankara. 